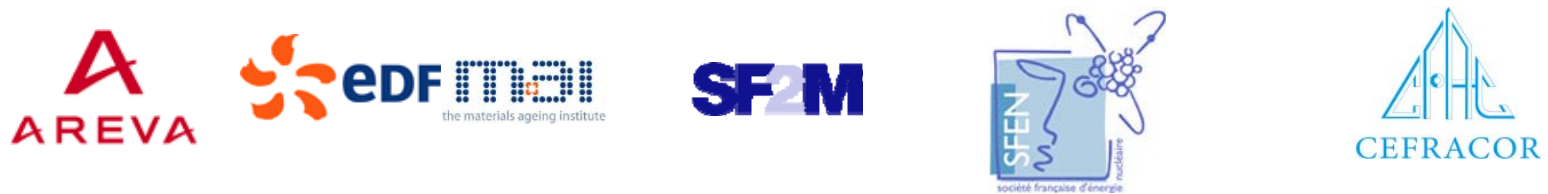

\section{MIN口S}

Centre of Excellence for Nuclear Materials

\section{Workshop}

Materials Innovation for Nuclear Optimized Systems
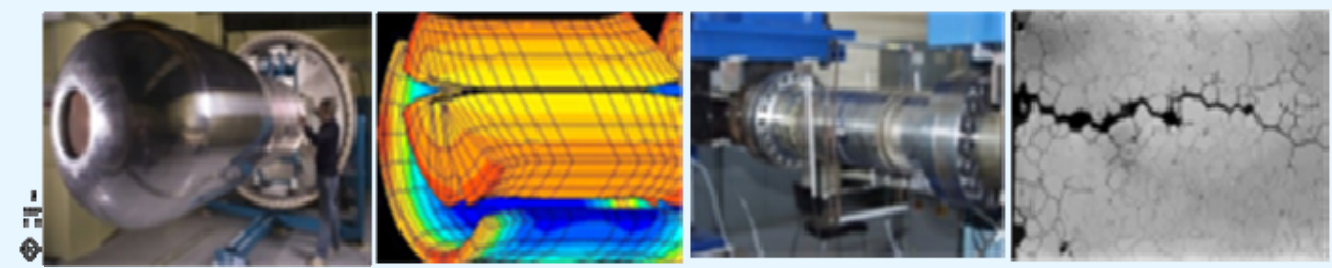

December 5-7, 2012, CEA - INSTN Saclay, France

\section{Françoise TOUBOUL et al. \\ CEA (France)}

ANCRE Alliance: Roadmap for Nuclear Materials

Workshop organized by:

Christophe GALLÉ, CEA/MINOS, Saclay - christophe.galle@cea.fr Constantin MEIS, CEA/INSTN, Saclay - constantin.meis@cea.fr 


\title{
ANCRE Alliance: Roadmap for Nuclear Materials
}

\author{
Françoise TOUBOUL ${ }^{1}$, Frank CARRÉ ${ }^{2}$ \\ ${ }^{1}$ CEA-DEN-DISN, Scientific and Technological Basic Research Program (Saclay, France) \\ ${ }^{2}$ CEA-DEN, Scientific Direction (Saclay, France)
}

\begin{abstract}
Created in 2009 by the Higher Education and Research ministry and by the Ecology ministry, ANCRE, the National Alliance for Energy Research Coordination aims at enhancing the efficiency of French research in the field of energy by promoting partnerships and synergies between public and private sectors (research organizations, universities and companies).
\end{abstract}

ANCRE aims to propose a coordinated strategy for research and innovation projects. Beyond its four founding members, CEA, CNRS, IFPEN and CPU, ANCRE brings together all the French public research organizations concerned with energy issues, and has strong links with the industrial sector.

Among the 10 programmatic groups of ANCRE, one is specifically dedicated to Nuclear Energies (fission and fusion). This group has proposed roadmaps in five scientific fields, considered as strategic for R\&D, in relation to industrial objectives and scientific bottlenecks: nuclear materials, nuclear chemistry, reactor physics, instrumentation and fusion.

For twenty to thirty years, R\&D on nuclear materials has evolved from the heavy metallurgy of the first generation of power reactors to the nano-materials science under extreme conditions for present and future needs. Nuclear systems are characterized by extreme operating conditions: high temperatures, mechanical stresses, radiations, corrosive environment, and long durations. In order to deal with these extreme conditions, it is necessary to have a sound knowledge of the materials, to the finest scale.

R\&D development was made possible by advances in materials science, in relation to more efficient observation means (now reaching the atom scale) and deeper control of the microstructure. Development of simulation methods at the atomic level (ab initio, classical molecular dynamics, kinetic Monte Carlo, etc.) have also allowed a better understanding of phenomena at their most fundamental level. Material performance issues, however, remain significant, as the performance targets have changed: more severe operating conditions (higher neutron fluence and very high temperature), and new objectives for reliability and security, in order to prevent and safely manage external aggressions (earthquake, aircraft impact, etc.) and severe internal accidents.

Manufacturers and researchers must rely on robust methods to assess and justify the lifetime of existing nuclear reactors, and to develop new materials (incrementally or leapfrogging) for current and future nuclear systems. Priority objectives have been defined by ANCRE members and subsequent scientific locks have been determined, leading to program proposals: material for reactor vessel or internal circuits, corrosion mechanisms, zirconium alloys, fuel materials, nano-reinforced steels, surface engineering, advanced metallurgical processes, composite materials, materials for fusion, refractory materials, containment materials (concrete, glass, clay), structural mechanics, multi-scale modeling and simulation, experiments.

At the same time they recommend directions for cooperative research, ANCRE roadmaps also identify existing laboratories able to contribute to these research goals, and suggest new research clusters or structures when appropriate, as well as other frameworks of cooperation at national, European or international level. ANCRE also recommends initiatives to tighten links between research and education. 
ANCRE roadmap on materials for nuclear energies fully concurs that multi-scale and multi-physics modeling and simulation tools based on the most accurate knowledge of physicochemical phenomena at various scales, together with characterization tools at the same scales, are of crucial importance for predicting materials performance and lifetime in service conditions, and for guiding research on materials for future nuclear systems. 


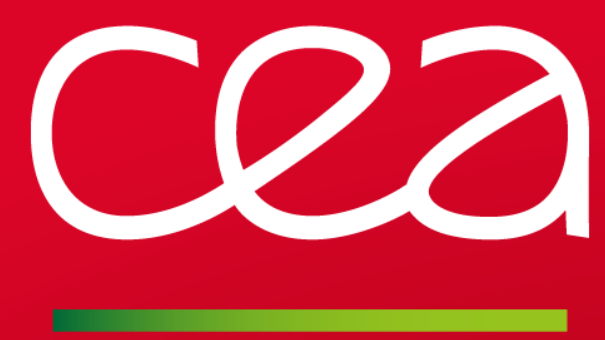

\section{ANCRE ALLIANCE : ROADMAP FOR NUCLEAR \\ MATERIALS}

\section{CPIS IRSLI Militury

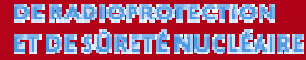

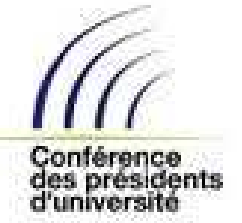

www.cea.fr
FRANÇOISE TOUBOUL, FRANK CARRE, CEA, SACLAY (FRANCE)

FRANCIS TEYSSANDIER, CNRS, LCTS 


\section{ANCRE alliance}

\section{MINDS}

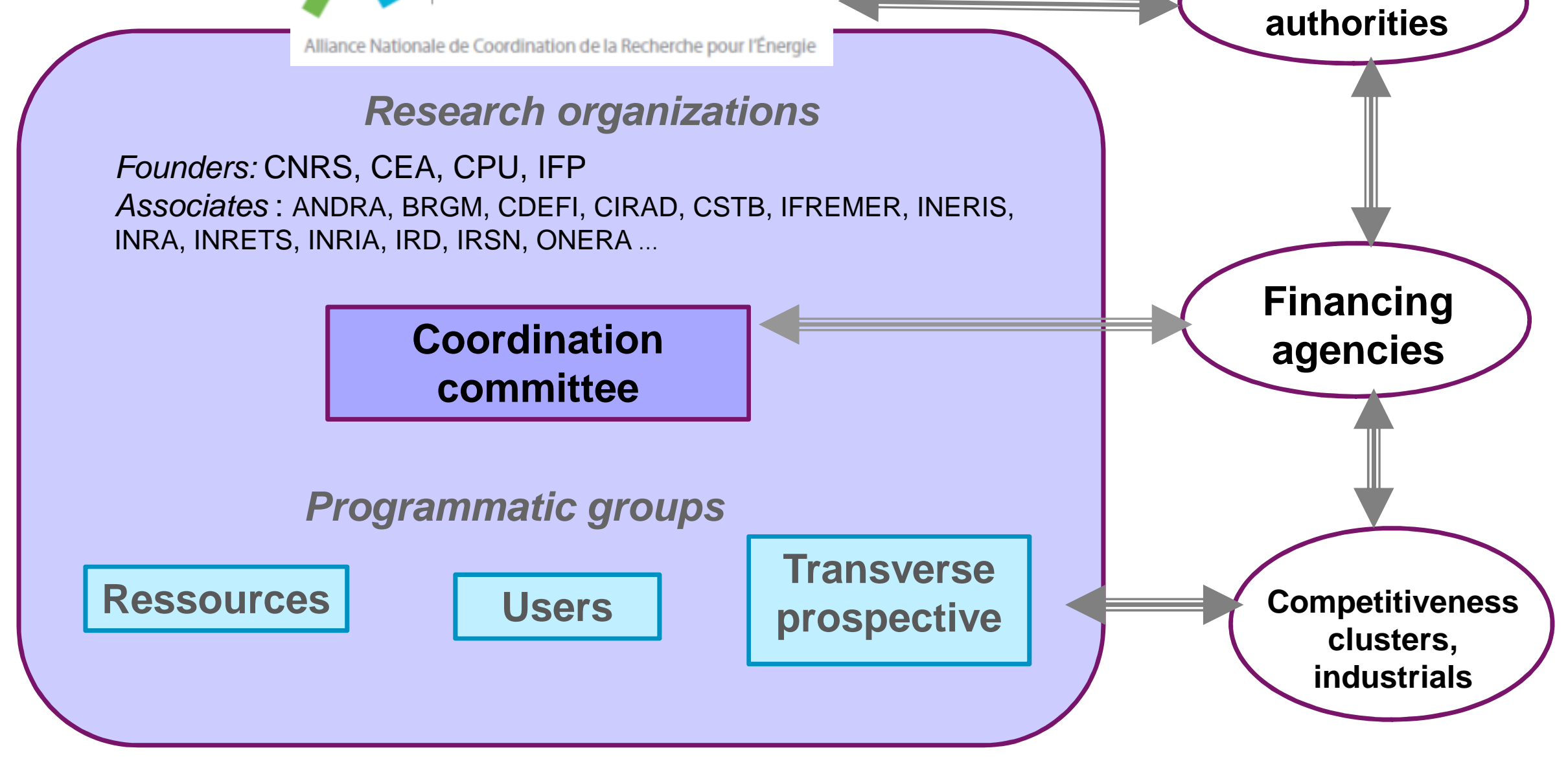




\section{ANCRE - programmatic groups}

\section{MIN口S}

\section{5 groups}

"Energy sources"

3 groups

"users"

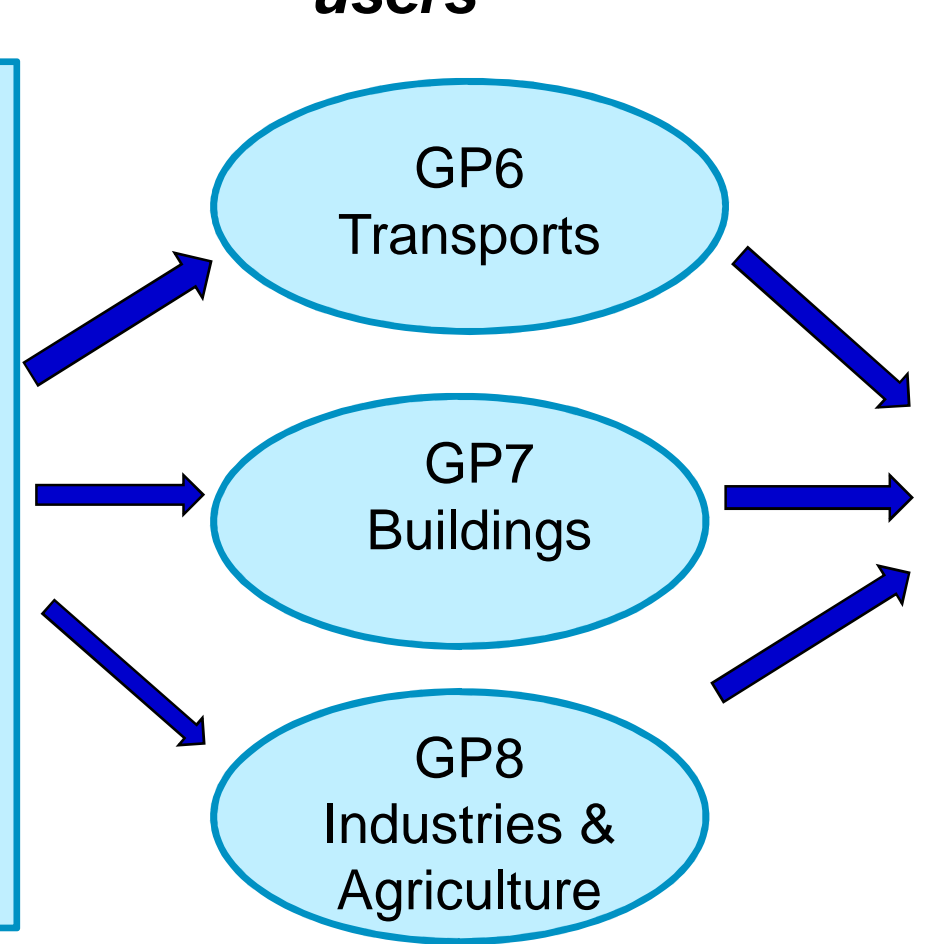

\section{Expected answers}

- Focused objectives

- Optimal paths

- Techniques

- Economics

- Environment

- Capacities

- Scientific, technical and societal breakthroughs

- roadmaps

\section{Energetic prospect (GP9)}




\section{ANCRE - GP3 : Nuclear energy}

MINDS

$P$ GP3 systems

2nd and 3rd generation reactors systems

- Fuels and fuel cycle for PWR

- $4^{\text {th }}$ generation reactor and cycle : FBR and GFR

- Watch on nuclear cogeneration + international prospective studies (RSF, Th, ADS)

- Fusion : ITER and R\&D DEMO

$>$ GP3 : key research area

Reactor physics and numerical simulation

- Nuclear Material

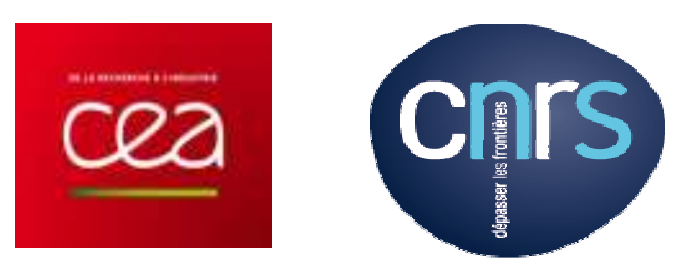

- Nuclear chemistry

- Instrumentation

- R\&D for fusion 


\section{Nuclear Material context}

MIN口S

- Nuclear material: extreme operating conditions $=>$ sound knowledge of the materials, to the finest scale

- advances in materials science : observation means, irradiation tools, simulation

new objectives for reliability and security

$=>$ prevent and securely manage external aggressions (earthquake, aircraft impact, etc.) and severe internal accidents.

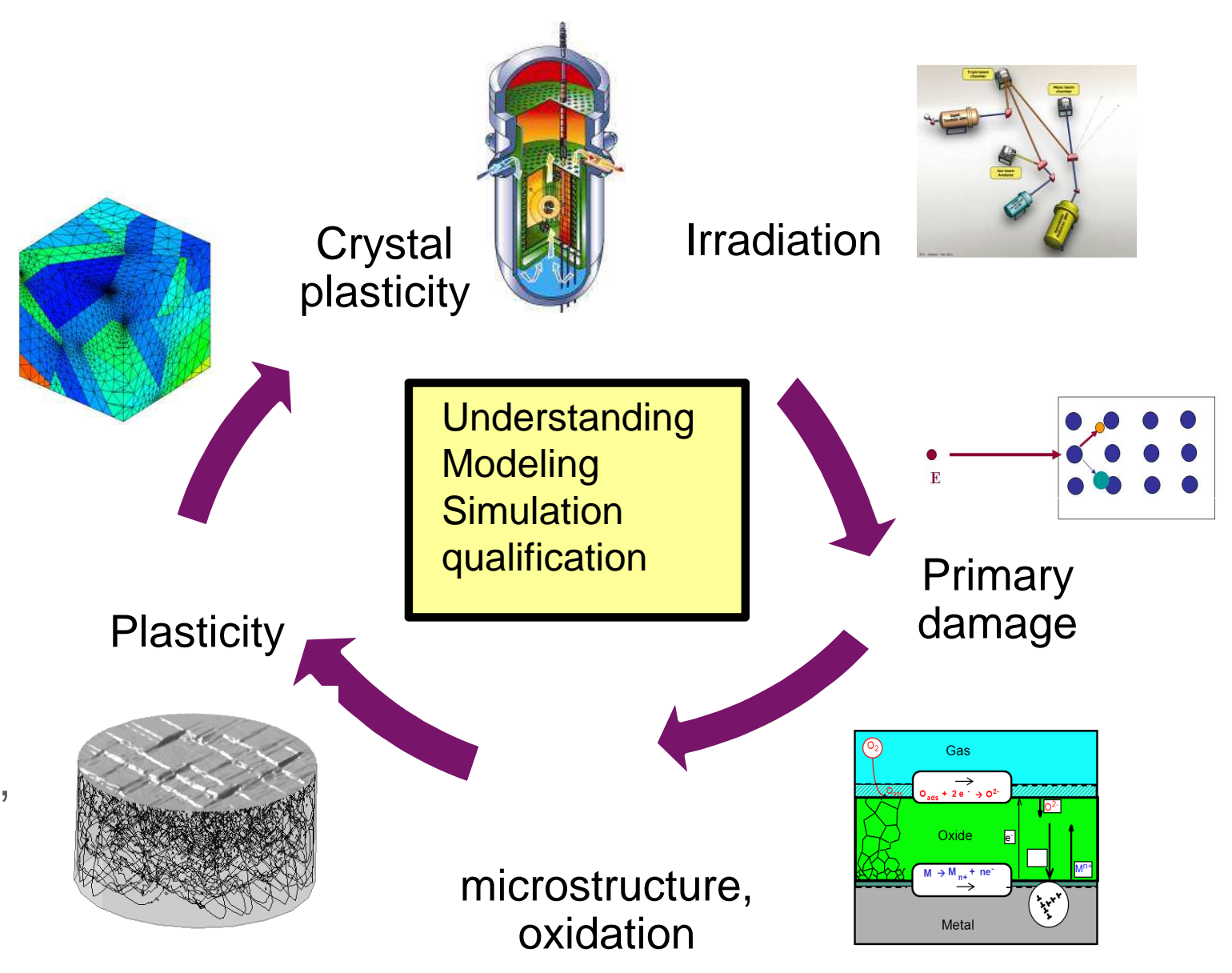




\section{Nuclear Material challenges}

(fission and fusion)

\section{MIN口S}

$>$ Challenges for nuclear reactors (CEA, IRSN, AREVA, EDF)

- Characterization of material ageing : PWR reactors and cycle facilities

- margins prediction under extreme conditions (environmental, loading)

$>$ scientific breakthroughs

- Multi-scale and multi-physics coupling simulation of materials, including dedicated experiments and qualification

- Development of new materials for fission reactors (steels, ODS, fuels, ceramics, glass, concrete, clay ...) and fusion (W alloys ...)

=> 2011 : ANCRE roadmap for nuclear material 


\section{ANCRE - Nuclear Material roadmap}

MINDS

For each industrial challenge : deadline, scientific breakthrough $=>$ $R \& D$ program

\begin{tabular}{|c|c|c|c|}
\hline challenge & horizon & breakthrough & $R \& D$ \\
\hline $\begin{array}{l}\text { REP } 900 \text { et } 1300 \mathrm{MW} \text {, } \\
\text { life extension }\end{array}$ & $\begin{array}{l}2015- \\
2020\end{array}$ & $\begin{array}{l}\text {-Validation of the } 60 \text { years extrapolation } \\
\text { (reactor vessel evaluation methods) } \\
\text {-Predictive modeling of swelling } \\
\text { (austenitic materials) } \\
\text {-Predictive modeling of general } \\
\text { corrosion and stress corrosion } \\
\text {-Modeling of seismic behavior "from the } \\
\text { fault to the structure" } \\
\text { - Instrumentation reliability under } \\
\text { extreme conditions }\end{array}$ & $\begin{array}{l}\text { - Vessel and internal } \\
\text { structure steels } \\
\text { - Corrosion mechanism } \\
\text { - Surface engineering } \\
\text { in extreme } \\
\text { environmental } \\
\text { conditions } \\
\text { - vibrations, dynamics }\end{array}$ \\
\hline
\end{tabular}




\section{ANCRE - Nuclear Material}

\section{MINDS}

\section{ANCRE program proposals}

- material for reactor Vessel or internal circuits,

- corrosion mechanisms,

E zirconium alloys, fuel materials,

I nano reinforced steels,

E surface engineering,

- advanced metallurgical process,

I composite materials,
- materials for fusion,

- refractory materials,

- containment materials (concrete, glass, clay),

I structural mechanics,

- Multi-scale modeling and simulation,

I experiments. 


\section{ANCRE - Nuclear Material}

MIN口S

\section{Main objectives}

Progress in materials modeling at different scales, taken into account physical bases :

Irradiation

temperature

Corrosion

mechanical, thermal loading

Integrate more recent advances in applied Mathematics, software Engineering and High Performance Computing

Develop smart experiments as well as global qualification devices

All structure or fuel materials:

Steel, alloys, ODS, ceramic, composites, Glass, concrete, UO2, ... 


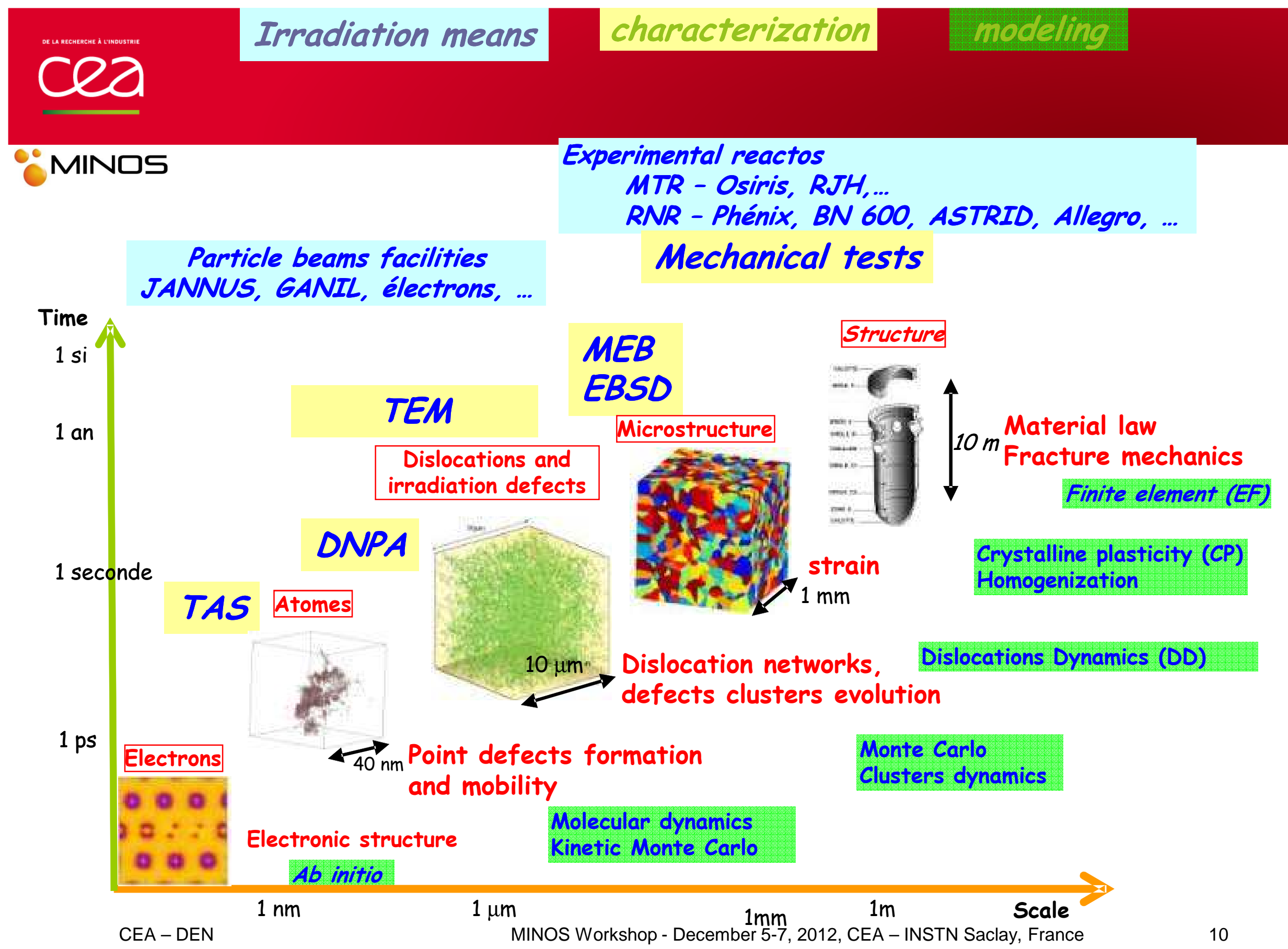




\section{ANCRE - Nuclear Material}

\section{MIN口S}

Example : ANCRE program proposal on Fuel material

Research priorities include

diffusion properties in actinide oxides: experimental and simulation

controlling the behavior under irradiation of the fuel matrix: thermal effects, defect behavior and fission products ...

general properties of fuel materials for Generation IV nuclear systems: thermodynamic properties and irradiation effects,

the role of additives, doping product and burnable poisons on the transport properties and the damaging effects,

Development and validation of atomic scale and mesoscopic modeling 


\section{ANCRE - Nuclear Material roadmap}

OMINDS

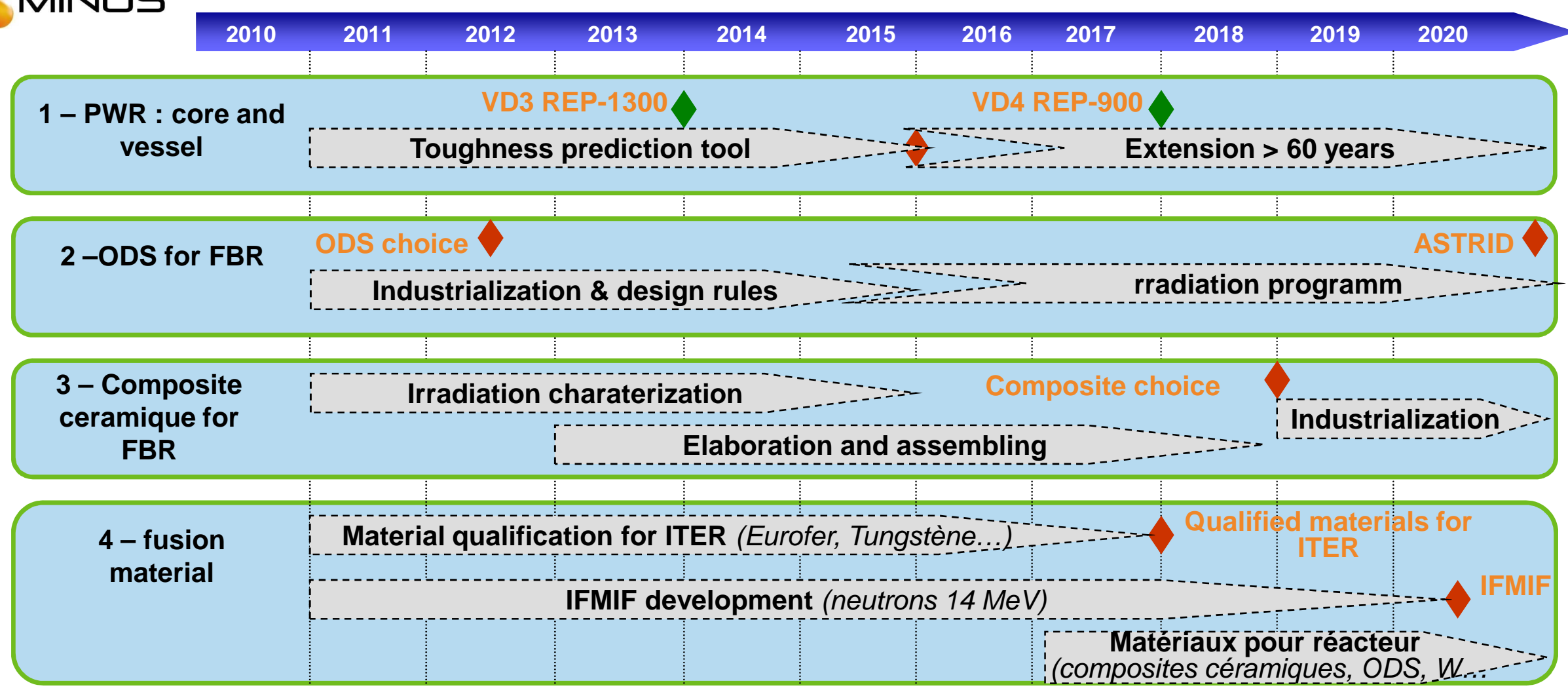

5 - modeling and numerical simulation

Multi scale modeling for steel

Multi scale modeling for ODS

Multi scale modeling for ceramic 


\section{ANCRE - Nuclear Material}

\section{MINDS}

\section{Structuring initiative}

- identify existing, or future, structures of the research community, in the term of permanent organization (with or without wall laboratories) or short term projects (national, European or international) :

- Research organization initiatives : NEEDS, MAI, MINOS, JANNUS, EMIR

- French initiatives : LASIPS, PALM, UPSa material network (Paris Saclay University)

- European initiatives : SPIRIT, CECAM

- International GDR Multiscale Materials Under the Nanoscope $\left(\mathrm{M}^{2} \subset \mathrm{N}\right)$ USA (MIT, U. Princeton, NIST, U. Berkeley), and Europe (U. Oxford, Labein-Bilbao, ETH Zurich) 


\section{Cea ANCRE - Nuclear Material}

MINDS

\section{Structuring initiative}

E tighten links between research and education : masters (MANUEN -Materials Science for Nuclear Energy /INPG, "Matériaux de structure pour l'énergie" /INSTN, $\mathrm{MNE}$ /paritech and al., ...), doctorate level (UPSa,...).

- tighten links between research organizations and competitiveness clusters (MATERALIA,ICB, $\mathrm{EMC2}, \ldots$.) 


\section{Cea ANCRE - Nuclear Material}

MIN口S

ANCRE roadmap for nuclear materials concludes on the necessity to use multi-scale and multi-physics modeling and simulation tools, based on the most accurate physical knowledge, accessible to a wide community of researchers and engineers, and associated with characterization tools at the same scales.

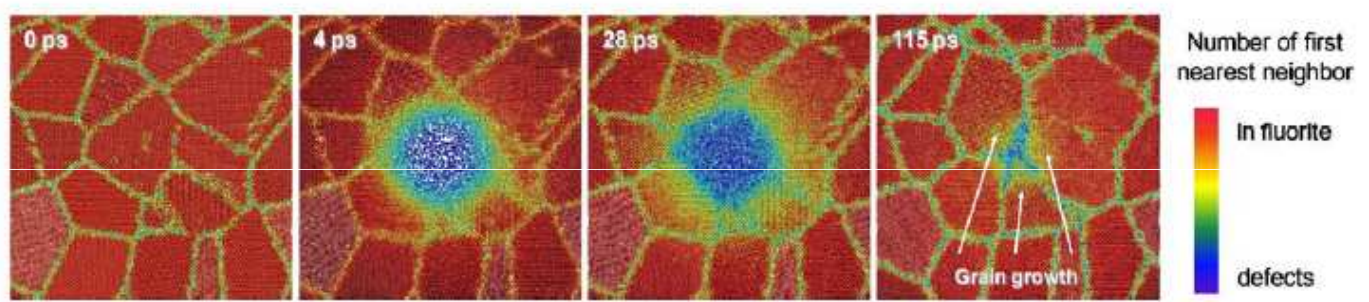

Snapshots of a thermal spike initiated with a $66 \mathrm{keV} / \mathrm{nm}$ energy in a polycrystal $\mathrm{UO}_{2}$

Swelling of REP internal structures

JANNUS irradiation CRESCENDO modeling

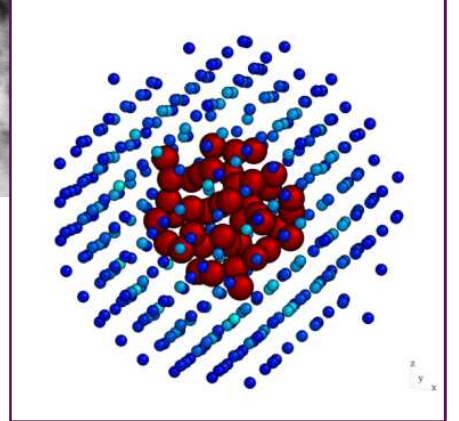

Reactor vessel DD modeling

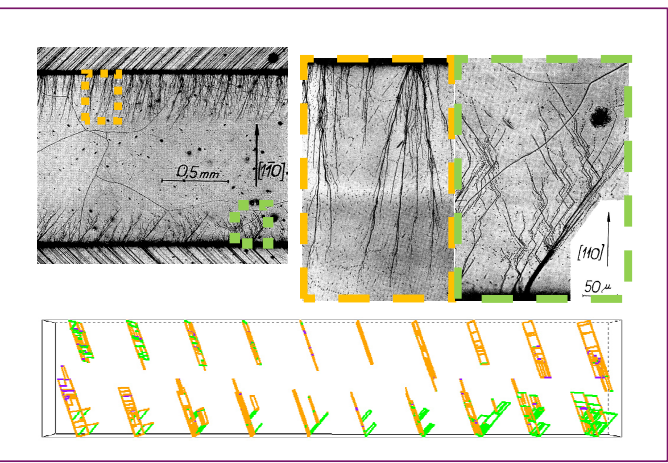




\section{cea \\ ANCRE}

$\because$ MINDS

A. ANCRE

Alliance Nationale de Cocrdination de la Recherche pour I'Energie

cirad

\section{INERIS}

$\frac{\text { ONERA }}{\text { THE FRENCH AEROSPACE LAB }}$

Ifremer
IFSTTAR
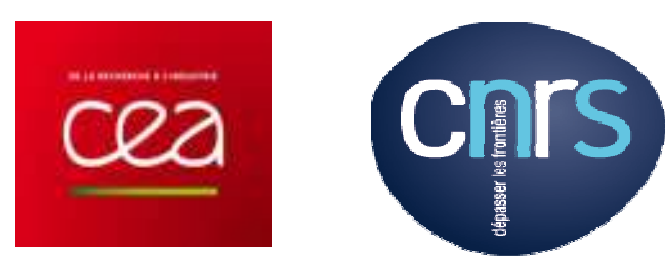

Uncía

\section{(N) INPA}

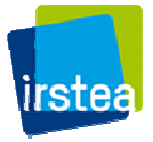

ค brgm

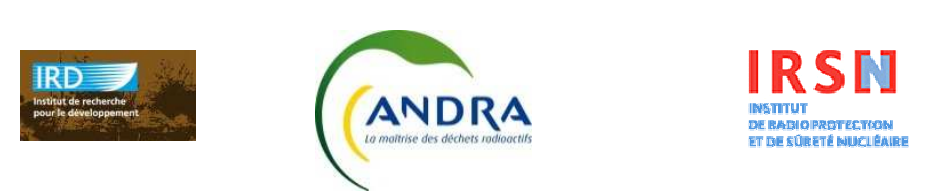

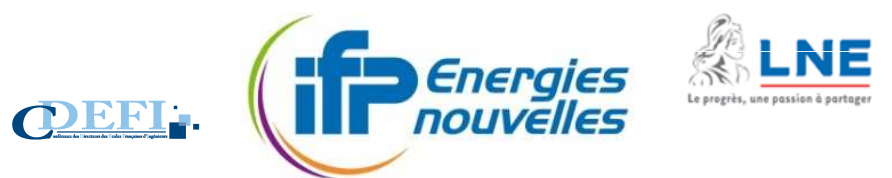

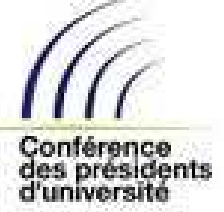

CSTB 